\title{
TARGETED TEMPERATURE MANAGEMENT: STATE OF THE ART
}

\author{
Lukasz Szarpak $^{1} \odot$, Jacek Smereka ${ }^{2} \odot$, Kurt Ruetzler ${ }^{3} \odot$ \\ ${ }^{1}$ Lazarski University, Warsaw, Poland \\ ${ }^{2}$ Department of Emergency Medical Service, Wroclaw Medical University, Wroclaw, Poland \\ ${ }^{3}$ Departments of Outcomes Research and General Anaesthesiology, Anaesthesiology Institute, Cleveland Clinic, Cleveland, Ohio, United States
}

\begin{abstract}
One of the indicated elements of post-resuscitation care is therapeutic hypothermia or temperature treatment management. the survivability of out-of-hospital cardiac arrest (OHCA) till admission to hospital is only $23 \%$. Efficient thermoregulatory mechanisms are the basis for maintaining optimal body temperature. Therapeutic hypothermia shows normalizing effect on metabolic processes disturbed in ischaemic conditions, including improving metabolism and maintaining glucose balance in the brain, lowering the concentration of lactates, limiting the secretion of free radicals in damaged neurons, lowering the production of pro-inflammatory cytokines, stabilizes the blood-brain barrier and reduces endothelial dysfunction preventing ischaemic damage to tissues and organs. Hypothermia has a wide multidirectional effect on the human body, which can be useful in patients. Most available scientific studies show the efficacy and benefits of hypothermia in patients with out-of-hospital sudden cardiac arrest, including especially with ventricular fibrillation. The delay in the initiation of therapeutic hypothermia and reaching target temperature significantly increased the odds of a poor neurological outcome. Current American Heart Association (AHA) and European Resuscitation Council (ERC) resuscitation guidelines recommend that targeted temperature management should be implemented in all adult coma patients with return of spontaneous circulation (ROCS) after sudden cardiac arrest. The target temperature should be between $32^{\circ} \mathrm{C}$ and $36^{\circ} \mathrm{C}$ and then maintained for at least 24 hours. In patients with coma after TTM, fever should be actively prevented. For patients with out-of-hospital cardiac arrest, it is not recommended to routinely cool patients in prehospital conditions with a rapid intravenous infusion of cold fluids after ROSC.
\end{abstract}

KEY WORDS: targeted temperature management, therapeutic hypothermia, cardiopulmonary resuscitation, post-resuscitation care

Disaster Emerg Med J 2019; 4(2): 68-73

\section{INTRODUCTION}

In Europe, sudden cardiac arrest occurs with a rate of 0.4 to 1 per 1000 people per year, affecting between 350000 and 700000 people [1]. The Sasson et al. study showed that the survivability of out-of-hospital cardiac arrest (OHCA) until admission to hospital is only $23 \%$ [2]. The resuscitation procedure itself is only one part of the treatment of a patient with cardiac arrest. Rescue procedures do not end when spontaneous circulation returns, but also include time after ROSC and are designed to stabilize the patient's condition and reduce organ damage from long-term hypoxia and inflammation. This can be confirmed by the guidelines of the American Heart Association, in which already in 2010 a separate chapter on post-resuscitation care 
was introduced [3]. One of the indicated elements of post-resuscitation care is therapeutic hypothermia or temperature treatment management. During the last decade, the introduction of mild therapeutic hypothermia has been demonstrated to improve neurological outcome and survival after out-of-hospital cardiac arrest due to ventricular fibrillation.

\section{Basics of thermoregulation}

Thermoregulation is the ability to maintain a constant body temperature regardless of the ambient temperature. Efficient thermoregulatory mechanisms are the basis for maintaining optimal body temperature. The best-known thermoregulatory model is the two-factor thermal model developed by Gagge et al. [4]. It consists of two concentric cylinders: external, so-called shell (skin, adipose tissue and muscles) with temperature in the range of 28-35 ${ }^{\circ} \mathrm{C}$, and internal, so-called cortex including the brain, abdominal organs and chest with a regulated temperature of about $37^{\circ} \mathrm{C}$. In this system, the skin acts as a buffer between the body and the external environment and is dependent on the heat exchange between these areas. The temperature signal is transmitted via thermosensitive, cation-selective ion channels, the so-called instantaneous potential receptors (TRP): vanilloid receptors (TRPV1-4) [5], heat-activated and melastatin-activated (TRPM8), activated by low temperatures [6-8]. Researchers, including Noël et al. [9] consider that other ionic channels also participate in low-temperature signal transmission: potassium channels with dual domains TRAAK and TREK1, which are activated by hyperpolarization and modulated by cyclic sodium and potassium nucleotides HCN1 channels [10]. The thermoregulatory processes can be divided into three stages: peripheral and cortical perception, central integration and autonomous and behavioural efferent response, while the information about temperature changes is transmitted inwardly through A $\delta$ fibres (cold feeling) and C fibres (heat feeling) modulated at the level of the spinal cord and brain stem. The heat transfer medium itself is made up of two heat transfer mediums: heat loss and heat retention. The first is located in the previsual anterior part of the hypothalamus and is responsible for reactions that increase heat elimination. The second medium is located in the posterior hypothalamus, responsible for reactions that reduce loss and at the same time increase the body's heat generation $[11,12]$. Therefore, thermoreceptors placed in the anterior hypothalamus are thermodetectors and react mainly to an increase in temperature, which determines the expansion of skin vascular and subcutaneous tissue and the intensification of sweat secretion. On the other hand, neurons located in the posterior hypothalamus do not have the character of thermodetectors but are a specific switch station for impulses from peripheral thermoreceptors. Their stimulation results in the release of chemical thermogenesis [13].

\section{Effect of hypothermia on the human body}

Therapeutic hypothermia shows normalizing effect on metabolic processes disturbed in ischaemic conditions, including improving metabolism and maintaining glucose balance in the brain, lowering the concentration of lactates formed as a result of anaerobic metabolism, reducing the intensity of cellular acidosis, limiting the secretion of free radicals in damaged neurons, lowering the production of pro-inflammatory cytokines (TNF- $\alpha$, IL-6), stabilizes the blood-brain barrier and reduces endothelial dysfunction preventing ischaemic damage to tissues and organs [14-18].

Hypothermia also increases the concentration of neurotrophins, including brain-derived neurotrophic factor (BDNF), as well as enhances angiogenesis in ischaemic areas, reducing also the effect of glutamate and other neurotransmitters, resulting from their excessive release in pathological states of the central nervous system [19-22]. In the hypothermia phase, apoptosis is also reduced, including modulation of MAP (mitogen-activated protein) kinases signal pathways, inhibition of TNF- $\alpha$ (tumour necrosis factor- $\alpha$ ) and caspase-induced proapoptotic cellular signal pathways, which play an important role in the regulation of programmable cell death, as well as lowering the level and activity of apoptosis-initiating proteins: p53-activator protein of apoptosis genes, calpain, cathepsins, granzymes, apoptosis-inducing factor (AIF) and C-delta protein kinase, with simultaneous increase of antiapoptotic factors: C-epsilon protein kinase, $\mathrm{BCl}-2$ protein and serine-threonine kinase Act [23-26].

\section{Studies on the effectiveness of therapeutic hypothermia}

The first reports on the use of therapeutic hypothermia in post-resuscitation care can be found in the 1958 study by Benson et al. [27]. In this study of 19 patients, 7 were subjected to therapeutic hypo- 
thermia. No significant neurological disorders were reported in this group, and in the case of the control group without hypothermia only in one of the seven patients, no significant neurological deficits were observed. The increase in global interest in therapeutic hypothermia as a therapeutic method dates back to the beginning of the 21st century when a large study by Bernard et al. was published. [28]. Also, the HACA trial indicated that patients who have been successfully resuscitated after cardiac arrest due to ventricular fibrillation, therapeutic mild hypothermia increased the rate of a favourable neurological outcome and reduced mortality [29].

Bernard's study included 77 patients who were randomly assigned to treatment with hypothermia (with the core body temperature reduced to $33^{\circ} \mathrm{C}$ within 2 hours after the return of spontaneous circulation and maintained at that temperature for 12 hours) or normothermia. 21 of the 43 patients treated with hypothermia (49\%) survived and had a good outcome - as compared with 9 of the 34 treated with normothermia (26\%). This difference was statistically significant $(P=0.046)$. In the case of Holzer, as in the case of Bernard et al. [28] patients in the hypothermia group had a favourable neurological outcome, as compared with the normothermia group.

The Storm et al. study showed that the use of therapeutic hypothermia was associated with a statistically significantly shorter stay in ICU stay and mechanical ventilation in survivors after OHCA. [30]. In other study Storm et al. [31] indicated that the early survival benefit seen with therapeutic hypothermia persists after two years. Moreover, neurological outcome significantly improved after mild hypothermia treatment (hypothermia group CPC 1-2 59.8\% vs. control group CPC 1-2 24.5\%).

A study published in the Emergency Medicine Journal [32] showed that neurological outcome in patients resuscitated from non-VF cardiac arrest with hypothermia compared to non-hypothermia group (CPC 1-2: $27.59 \%$ vs $18.20 \%$, respectively).

The Nielsen et al. study has introduced a great amount of confusion in the use of therapeutic hypothermia [33] comparing two target temperatures $\left(33^{\circ} \mathrm{C}\right.$ or $\left.36^{\circ} \mathrm{C}\right)$. In this study in unconscious survivors of out-of-hospital cardiac arrest of presumed cardiac cause, hypothermia at a targeted temperature of $33^{\circ} \mathrm{C}$ did not confer a benefit as compared with a temperature of $36^{\circ} \mathrm{C}$. However, because of the ambiguous conclusions reached, that study is often over-interpreted. Nielsen indicates a temperature of $36^{\circ} \mathrm{C}$ as normothermia, however, due to the fact that RSCA is usually followed by fever, a temperature of $36^{\circ} \mathrm{C}$ can be considered to induce hypothermia.

\section{PATIENT COOLING METHODS}

The study of Arrich et al. [34] included 650 patients from 19 sites within Europe. 462 of all patients (79\%) received therapeutic hypothermia, 347 (59\%) were cooled with an endovascular device, and 114 (19\%) received other cooling methods such as ice packs, cooling blankets, and cold fluids. The median cooling rate was 1.1 degrees $C$ per hour. An important but logical result of studies conducted by Arrich et al. was a shorter time to initiate cooling from the return of spontaneous circulation in case of non-invasive cooling methods [34]. Median time from ROSC to initiation of cooling using endovascular cooling was 150 minutes (IQR; 94-226), and in the case of another cooling method -75 minutes (IQR; 26-130). Maze et al. carrying out a retrospective cohort study on consecutive patients indicated that the use of endovascular catheters for induction of therapeutic hypothermia was associated with a high rate of catheter-related thrombosis [35].

In turn, Mooney et al. indicated that simple cooling with ice bags initiated soon after an arrest can be associated with incrementally improved outcomes, even if transfer to a specialized therapeutic hypothermia (TH) centre is required [36]. Study of Sendelbach et al. demonstrated that both the delay in initiation of therapeutic hypothermia as well as the delay in reaching target temperature significantly increased the odds of a poor (Cerebral Performance Category, CPC 3-5) compared to (CPC 1) neurological outcome [37].

Comparison of the impact of cooling with Coolgard (Zoll Medical Corporation, Chelmsford, MA, USA) and Surface cooling ArticSun ${ }^{\circledR}$ (Medivance Inc., Louisville, CO, USA; Fig. 1 and 2) was taken on by the team of Pittl et al. [38]. Using both types of cooling devices, comparable survival and neurological status of patients was achieved, however, bleeding complications were more frequently encountered by invasive cooling.

\section{Therapeutic hypothermia in the framework of resuscitation guidelines}

International Liaison Committee on Resuscitation, American Heart Association as well as the European 


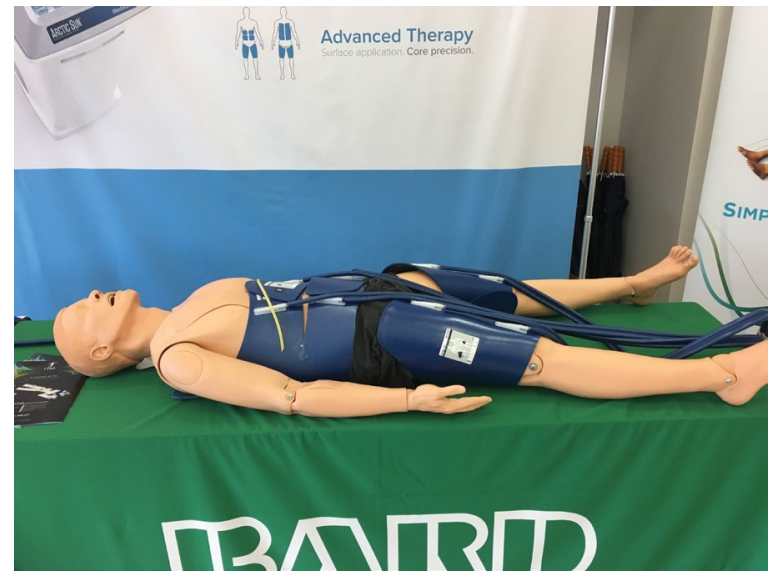

FIGURE 1. Cooling pads of ArticSun ${ }^{\circledR}$ on manikin

Resuscitation Council for the first time introduced therapeutic hypothermia as a therapeutic method into post-resuscitation care in 2005. AHA then assigned this method to Class Ila and ILCOR and ERC to Class I. According to the 2010 guidelines, TTM was used in patients with ROSC after out-of-hospital sudden cardiac arrest in ventricular fibrillation, and the target temperature was $32^{\circ} \mathrm{C}$ to $34^{\circ} \mathrm{C}$ and was maintained from 12 to 24 hours.

Current American Heart Association (AHA) and European Resuscitation Council (ERC) resuscitation guidelines recommend that targeted temperature management should be implemented in all adult coma patients with return of spontaneous circulation (ROCS) after sudden cardiac arrest. The target temperature should be between $32^{\circ} \mathrm{C}$ and $36^{\circ} \mathrm{C}$ and then maintained for at least 24 hours.

In patients with coma after TTM, fever should be actively prevented.

For patients with out-of-hospital cardiac arrest, it is not recommended to routinely cool patients in prehospital conditions with a rapid intravenous infusion of cold fluids after ROSC.

\section{CONCLUSIONS}

Hypothermia has a wide multidirectional effect on the human body, which can be useful in patients. Most available scientific studies show the efficacy and benefits of hypothermia in patients with out-of-hospital sudden cardiac arrest, including especially with ventricular fibrillation. The delay in the initiation of therapeutic hypothermia and reaching target temperature significantly increased the odds of a poor neurological outcome. Current American

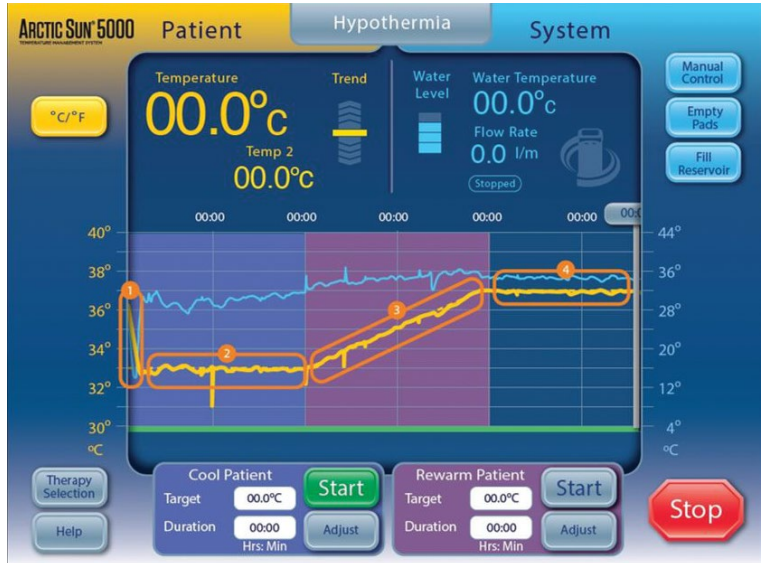

FIGURE 2. Example of device for TTM — Surface cooling ArticSun ${ }^{\circledR}$

Heart Association (AHA) and European Resuscitation Council (ERC) resuscitation guidelines recommend that targeted temperature management should be implemented in all adult coma patients with return of spontaneous circulation (ROCS) after sudden cardiac arrest. However, the controlled heating of the patient after the TTM procedure should not be forgotten either. The ERC recommends restoring normal body temperature at $0.25-0.5^{\circ} \mathrm{C} / \mathrm{h}[1]$. After heating, it is necessary to prevent temperature increases and fever, which may eliminate the beneficial effects of hypothermia by increasing the need for oxygen and nutrients in tissues and organs, including the central nervous system.

\section{REFERENCES}

1. Lippert FK, Raffay V, Georgiou M, et al. European Resuscitation Council Guidelines for Resuscitation 2010 Section 10. The ethics of resuscitation and end-of-life decisions. Resuscitation. 2010; 81(10): 1445-1451, doi: 10.1016/j.resuscitation.2010.08.013, indexed in Pubmed: 20956043.

2. Sasson C, Rogers MAM, Dahl J, et al. Predictors of survival from out-of-hospital cardiac arrest: a systematic review and meta-analysis. Circ Cardiovasc Qual Outcomes. 2010; 3(1): 63-81, doi: 10.1161/ CIRCOUTCOMES.109.889576, indexed in Pubmed: 20123673.

3. Peberdy MA, Callaway CW, Neumar RW, et al. American Heart Association. Part 9: post-cardiac arrest care: 2010 American Heart Association Guidelines for Cardiopulmonary Resuscitation and Emergency Cardiovascular Care. Circulation. 2010; 122(18 Suppl 3): S768-S786, doi: 10.1161/CIRCULATIONAHA.110.971002, indexed in Pubmed: 20956225.

4. Gagge AP, Fobelets AP, Berglund LG. A standard predictive index of human response to the thermal environment. ASHARE Trans. 1986; 92: 709-711.

5. Luo $Y$, Sun $W$, Feng $X$, et al. (-)-menthol increases excitatory transmission by activating both TRPM8 and TRPA1 channels in mouse 
spinal lamina II layer. Biochem Biophys Res Commun. 2019; 516(3): 825-830, doi: 10.1016/j.bbrc.2019.06.135, indexed in Pubmed: 31262448.

6. Blanquart $S$, Borowiec AS, Delcourt $P$, et al. Evolution of the human cold/menthol receptor, TRPM8. Mol Phylogenet Evol. 2019; 136: 104-118, doi: 10.1016/j.ympev.2019.04.011, indexed in Pubmed: 30980935.

7. Ordás $\mathrm{P}$, Hernández-Ortego $\mathrm{P}$, Vara $\mathrm{H}$, et al. Expression of the cold thermoreceptor TRPM8 in rodent brain thermoregulatory circuits. J Comp Neurol. 2019 [Epub ahead of print], doi: 10.1002/cne.24694, indexed in Pubmed: 30942489.

8. $\mathrm{Xu} X$, Tikuisis $P$. Thermoregulatory modeling for cold stress. Compr Physiol. 2014; 4(3): 1057-1081, doi: 10.1002/cphy.c130047, indexed in Pubmed: 24944030.

9. Noël J, Zimmermann K, Busserolles J, et al. The mechano-activated K+ channels TRAAK and TREK-1 control both warm and cold perception. EMBO J. 2009; 28(9): 1308-1318, doi: 10.1038/emboj.2009.57, indexed in Pubmed: 19279663.

10. Stebe $S$, Schellig K, Lesage $F$, et al. The thermosensitive potassium channel TREK-1 contributes to coolness-evoked responses of Grueneberg ganglion neurons. Cell Mol Neurobiol. 2014; 34(1): 113-122, doi: 10.1007/s10571-013-9992-x, indexed in Pubmed: 24101433.

11. Reimúndez A, Fernández-Peña $C$, García $G$, et al. Deletion of the Cold Thermoreceptor TRPM8 Increases Heat Loss and Food Intake Leading to Reduced Body Temperature and Obesity in Mice. J Neurosci. 2018; 38(15): 3643-3656, doi: 10.1523/JNEUROSCI.3002-17.2018, indexed in Pubmed: 29530988.

12. Romanovsky AA. The thermoregulation system and how it works. Handb Clin Neurol. 2018; 156: 3-43, doi: 10.1016/B978-0-44463912-7.00001-1, indexed in Pubmed: 30454596.

13. Lenhardt R. Body temperature regulation and anesthesia. Handb Clin Neurol. 2018; 157: 635-644, doi: 10.1016/B978-0-444-640741.00037-9, indexed in Pubmed: 30459029.

14. Zhang HB, Cheng SX, Tu Y, et al. Protective effect of mild-induced hypothermia against moderate traumatic brain injury in rats involved in necroptotic and apoptotic pathways. Brain Inj. 2017; 31(3): 406-415, doi: 10.1080/02699052.2016.1225984, indexed in Pubmed: 28140659.

15. Zhao K, Li R, Bi S, et al. Combination of mild therapeutic hypothermia and adipose-derived stem cells for ischemic brain injury. Neural Regen Res. 2018; 13(10): 1759-1770, doi: 10.4103/1673-5374.238617, indexed in Pubmed: 30136691.

16. Zhao CC, Wang CF, Li WP, et al. Mild Hypothermia Promotes Pericontusion Neuronal Sprouting via Suppressing Suppressor of Cytokine Signaling 3 Expression after Moderate Traumatic Brain Injury. J Neurotrauma. 2017; 34(8): 1636-1644, doi: 10.1089/neu.2016.4759, indexed in Pubmed: 27923323.

17. Torres $M$, Zúñiga $R$, Gutierrez $M$, et al. Mild hypothermia upregulates myc and xbp1s expression and improves anti-TNF production in CHO cells. PLoS One. 2018; 13(3): e0194510, doi: 10.1371/journal. pone.0194510, indexed in Pubmed: 29566086.
18. Guillot $X$, Martin H, Seguin-PyS, et al. Local cryotherapy improves adjuvant-induced arthritis through down-regulation of IL-6 / IL-17 pathway but independently of TNF . PLoS One. 2017; 12(7): e0178668, doi: 10.1371/journal.pone.0178668, indexed in Pubmed: 28759646.

19. Shaikh H, Boudes E, Khoja Z, et al. Angiogenesis dysregulation in term asphyxiated newborns treated with hypothermia. PLoS One. 2015; 10(5): e0128028, doi: 10.1371/journal.pone.0128028, indexed in Pubmed: 25996847.

20. Shaikh $H$, Lechpammer M, Jensen FE, et al. Increased Brain Perfusion Persists over the First Month of Life in Term Asphyxiated Newborns Treated with Hypothermia: Does it Reflect Activated Angiogenesis? Transl Stroke Res. 2015; 6(3): 224-233, doi: 10.1007/s12975-0150387-9, indexed in Pubmed: 25620793.

21. Yenari MA, Han HS. Influence of therapeutic hypothermia on regeneration after cerebral ischemia. Front Neurol Neurosci. 2013; 32: 122-128, doi: 10.1159/000346428, indexed in Pubmed: 23859971.

22. Xie YC, Li CY, Li T, et al. Effect of mild hypothermia on angiogenesis in rats with focal cerebral ischemia. Neurosci Lett. 2007; 422(2): 87-90, doi: 10.1016/j.neulet.2007.03.072, indexed in Pubmed: 17630209.

23. Ikonomidou C, Kirvassilis G, Swiney BS, et al. Mild hypothermia ameliorates anesthesia toxicity in the neonatal macaque brain. Neurobiol Dis. 2019 [Epub ahead of print]; 130: 104489, doi: 10.1016/j. nbd.2019.104489, indexed in Pubmed: 31175984.

24. Huun MU, Garberg H, Løberg EM, et al. DHA and therapeutic hypothermia in a short-term follow-up piglet model of hypoxia-ischemia: Effects on H+MRS biomarkers. PLoS One. 2018; 13(8): e0201895, doi: 10.1371/journal.pone.0201895, indexed in Pubmed: 30086156.

25. Wang $\mathrm{CF}$, Zhao CC, He Yi, et al. Mild hypothermia reduces endoplasmic reticulum stress-induced apoptosis and improves neuronal functions after severe traumatic brain injury. Brain Behav. 2019; 9(4): e01248, doi: 10.1002/brb3.1248, indexed in Pubmed: 30834702.

26. Yu $H$, Wang $L$, Zhang $H$, et al. Effect of mild hypothermia on cerebral microcirculation in a murine cardiopulmonary resuscitation model. Microcirculation. 2019 [Epub ahead of print], doi: 10.1111/micc.12537, indexed in Pubmed: 30801897.

27. Benson DW, Williams GR, Spencer FC, et al. The use of hypothermia after cardiac arrest. Anesth Analg. 1959; 38: 423-428, indexed in Pubmed: 13798997.

28. Bernard SA, Gray TW, Buist MD, et al. Treatment of comatose survivors of out-of-hospital cardiac arrest with induced hypothermia. N Engl J Med. 2002; 346(8): 557-563, doi: 10.1056/NEJMoa003289, indexed in Pubmed: 11856794.

29. Hypothermia after Cardiac Arrest Study Group. Mild therapeutic hypothermia to improve the neurologic outcome after cardiac arrest. N Engl J Med. 2002; 346(8): 549-556.

30. Storm C, Steffen I, Schefold JC, et al. Mild therapeutic hypothermia shortens intensive care unit stay of survivors after out-of-hospital cardiac arrest compared to historical controls. Crit Care. 2008; 12(3): R78, doi: 10.1186/cc6925, indexed in Pubmed: 18554414.

31. Storm C, Nee J, Krueger A, et al. 2-year survival of patients undergoing mild hypothermia treatment after ventricular fibrillation cardiac arrest 
is significantly improved compared to historical controls. Scand J Trauma Resusc Emerg Med. 2010; 18: 2, doi: 10.1186/1757-7241-18-2, indexed in Pubmed: 20064213.

32. Storm C, Nee J, Roser M, et al. Mild hypothermia treatment in patients resuscitated from non-shockable cardiac arrest. Emerg Med J. 2012; 29(2): 100-103, doi: 10.1136/emj.2010.105171, indexed in Pubmed: 21362725.

33. Nielsen N, Wetterslev J, Cronberg T, et al. Targeted Temperature Management at $33^{\circ} \mathrm{C}$ versus $36^{\circ} \mathrm{C}$ after Cardiac Arrest. N Engl J Med. 2013; 369(23): 2197-2206, doi: 10.1056/nejmoa1310519.

34. Arrich J. European Resuscitation Council Hypothermia After Cardiac Arrest Registry Study Group. Clinical application of mild therapeutic hypothermia after cardiac arrest. Crit Care Med. 2007; 35(4): 1041-1047, doi: 10.1097/01.CCM.0000259383.48324.35, indexed in Pubmed: 17334257.

35. Maze R, Le May MR, Froeschl M, et al. CArdiovascular Percutaneous Intervention TriAL (CAPITAL) investigators. Endovascular cooling catheter related thrombosis in patients undergoing therapeutic hypo- thermia for out of hospital cardiac arrest. Resuscitation. 2014; 85(10): 1354-1358, doi: 10.1016/j.resuscitation.2014.05.029, indexed in Pubmed: 24978111.

36. Mooney MR, Unger BT, Boland LL, et al. Therapeutic hypothermia after out-of-hospital cardiac arrest: evaluation of a regional system to increase access to cooling. Circulation. 2011; 124(2): 206-214, doi: 10.1161/CIRCULATIONAHA.110.986257, indexed in Pubmed: 21747066.

37. Sendelbach S, Hearst MO, Johnson PJo, et al. Effects of variation in temperature management on cerebral performance category scores in patients who received therapeutic hypothermia post cardiac arrest. Resuscitation. 2012; 83(7): 829-834, doi: 10.1016/j.resuscitation.2011.12.026, indexed in Pubmed: 22230942.

38. Pittl U, Schratter A, Desch S, et al. Invasive versus non-invasive cooling after in- and out-of-hospital cardiac arrest: a randomized trial. Clin Res Cardiol. 2013; 102(8): 607-614, doi: 10.1007/s00392-013-0572-3, indexed in Pubmed: 23644718. 